\title{
Digital Clubbing
}

National Cancer Institute

\section{Source}

National Cancer Institute. Digital Clubbing. NCI Thesaurus. Code C85489.

An enlargement of the tips of the fingers or toes and a change in the angle where the nails emerge. It occurs when the amount of soft tissue beneath the nail beds increases.

It may be idiopathic, hereditary, or associated with a wide range of diseases, including cardiopulmonary disorders and malignant neoplasms. 